\title{
Total homocysteine levels and cardiovascular risk factors in healthy Tunisians
}

M. El Oudi, ${ }^{1}$ Z. Aouni, ${ }^{1}$ C. Mazigh ${ }^{7}$ and S. Machghoul'

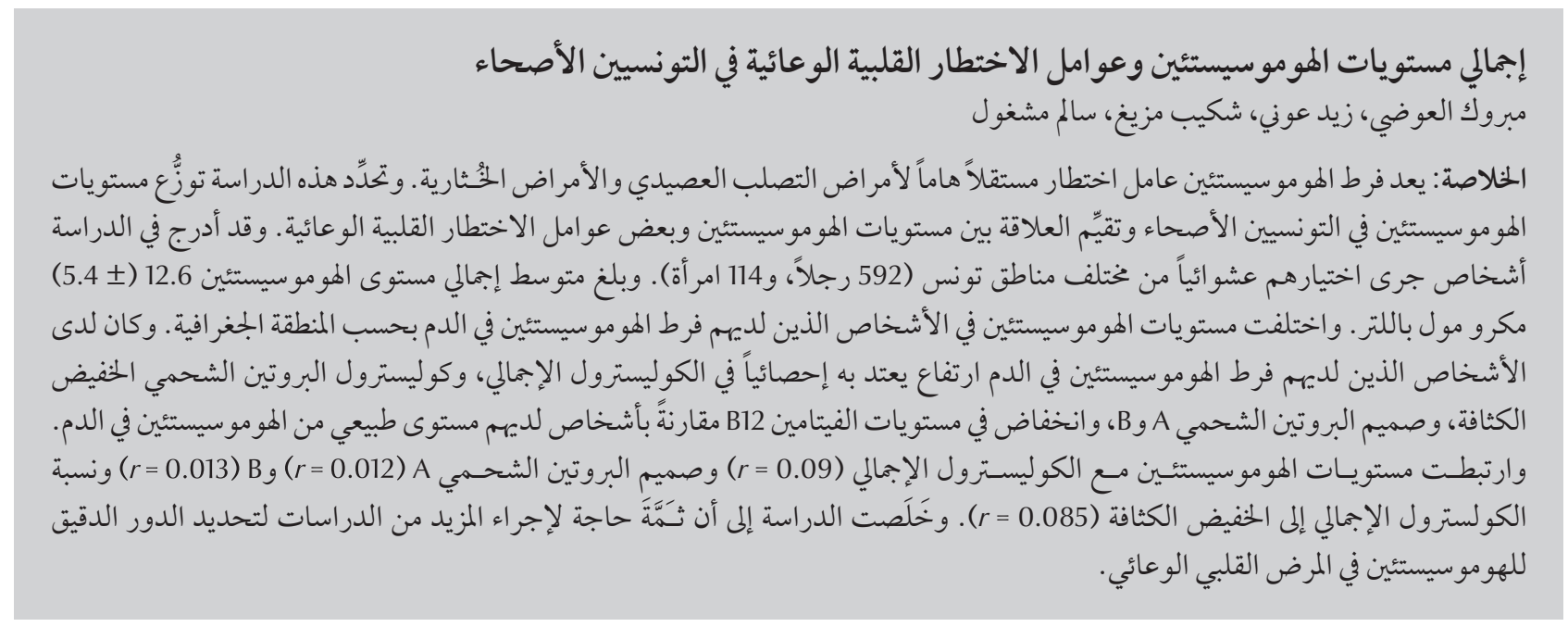

ABSTRACT Hyperhomocysteinaemia is considered as an important independent risk factor for atherosclerosis and thrombotic disease. This study determined the distribution of homocysteine (Hcy) levels in healthy Tunisian subjects and evaluated the relationship between Hcy levels and some cardiovascular risk factors. Randomly selected subjects (592 men and 114 women) were recruited from different regions of Tunisia. The overall mean Hcy level was 12.6 (SD 5.4) $\mu \mathrm{mol} / \mathrm{L}$. Hcy levels in subjects with hyperhomocysteinaemia varied according to geographical region. Subjects with hyperhomocysteinaemia had significantly elevated total cholesterol, LDL cholesterol, apolipoprotein A and apolipoprotein B and lower vitamin $B_{12}$ levels compared with subjects with normohomocysteinaemia. Hcy levels correlated with total cholesterol $(r=0.09)$, apolipoprotein A $(r=0.012)$, and B ( $r=0.013)$ levels and total/HDL cholesterol ratio $(r=-0.085)$. Further epidemiological studies are needed to determine the precise role of Hcy in cardiovascular disease.

Taux d'homocystéine totale et facteurs de risque cardio-vasculaires chez des Tunisiens en bonne santé

RÉSUMÉ L'hyperhomocystéinémie est considérée comme un important facteur de risque indépendant pour l'athérosclérose et la maladie thrombotique. La présente étude a déterminé la répartition des taux d'homocystéine chez des sujets tunisiens en bonne santé et a évalué la relation entre ce taux et certains facteurs de risque cardio-vasculaires. Des sujets ont été sélectionnés aléatoirement (592 hommes et 114 femmes) à partir de plusieurs régions de Tunisie. Le taux moyen d'homocystéine était de 12,6 $\mu$ mol/I (E.T. 5,4). Le taux d'homocystéine chez les sujets atteints d’hyperhomocystéinémie variait en fonction de leur région géographique. Les sujets atteints d’hyperhomocystéinémie présentaient des taux de cholestérol total, de cholestérol des lipoprotéines de basse densité, d'apolipoprotéine A et d'apolipoprotéine B très élevés ainsi que des taux moindres de vitamine $B_{12}$ par rapport aux sujets ayant un taux normal. Les taux d'homocystéine étaient corrélés aux taux de cholestérol total $(r=0,09)$, d'apolipoprotéine $\mathrm{A}(r=0,012)$ et d'apolipoprotéine $\mathrm{B}(r=0,013)$ ainsi qu'au rapport entre le cholestérol total et le cholestérol des lipoprotéines de basse densité $(r=-0,085)$. Des études épidémiologiques supplémentaires sont nécessaires pour déterminer le rôle précis de l’homocystéine dans les maladies cardio-vasculaires. 


\section{Introduction}

Elevated homocysteine (Hcy) concentration has been demonstrated to be a risk factor for cardiovascular disease (CVD) $[1,2]$. Evidence now indicates that hyperhomocysteinaemia (Hcy level $>15 \mu \mathrm{mol} / \mathrm{L}$ ) is an important independent risk factor for atherosclerosis and thrombotic disease [3]. Although the distribution of plasma concentrations of Hcy has been well reported in some populations in America and Europe, there are no epidemiological studies of Hcy concentrations in healthy subjects from different regions in Tunisia and their impact on CVD risk factors.

In the present study, we aimed to determine the distribution of plasma Hcy levels in healthy Tunisian subjects and to evaluate the relationship between Hcy levels and CVD risk factors.

\section{Methods}

\section{Sample}

In the present study 706 healthy young adults (592 men and 114 women) were randomly recruited from different regions of Tunisia. Their mean age was 28.0 [standard deviation (SD) 9.1] years old, range 20-71 years. We subdivided subjects into groups according to their geographical origin of residence: north $(n=361)$, Tunis (the capital) $(n=178)$, centre $(n=115)$ and south $(n=52)$. Exclusion criteria for participants were diabetes mellitus, hypertension, cardiomyopathy, renal failure and current use of vitamins. The study was approved by the local ethics committee and all subjects gave their consent to participate.

\section{Data collection}

A questionnaire was completed for each subject about demographic information (age, sex, weight, height, smoking, alcohol consumption). Cigarette smokers were categorized as current smokers (54.2\%) or non-smokers (including never smokers and ex-smokers who had quit smoking for at least 6 months before the study). Alcohol consumption was defined as consumers (12.9\%) or not of any alcoholic beverages. Body mass index (BMI) was calculated as weight $(\mathrm{kg}) /$ height $\left(\mathrm{m}^{2}\right)$.

Blood samples were collected from subjects after 12 hours offasting. Concentrations of Hcy in plasma were assessed using an automatic analyser (Immulite 2000, Diagnostic Products Corporation) based on a competitive immunoassay and were expressed in $\mu \mathrm{mol} / \mathrm{L}$. Serum vitamin $B_{12}$ and folate levels were measured by the autoanalyser based on a competitive immunoassay. Vitamin $B_{12}$ and folate levels were expressed in pg/ $\mathrm{mL}$ and $\mathrm{ng} / \mathrm{mL}$ respectively.

Total cholesterol, triglycerides (TG) and high-density lipoprotein (HDL) cholesterol were assessed by colorimetric enzymatic method (Technicom analyser, RA-1000, Dade Behring). Low-density lipoprotein (LDL) cholesterol was calculated by the Friedwald formula: LDL cholesterol $=$ total cholesterol (HDL cholesterol + TG/2.18) for TG $<4.5 \mathrm{mmol} / \mathrm{L}$. Apolipoprotein A, apolipoprotein B and lipoprotein (a) were assessed by the nephelometric method and the results were expressed in $\mathrm{g} / \mathrm{L}$.

The definition of normohomocysteinaemia was Hcy $\leq 15 \mu \mathrm{mol} / \mathrm{L}$ and hyperhomocysteinaemia was Hcy $>15$ $\mu \mathrm{mol} / \mathrm{L}$.

\section{Statistical analysis}

Statistical analyses were performed by SPSS, version 10.0 for Windows. Continuous variables are presented as mean and SD, and qualitative variables as relative frequencies. Kolmogorov-Smirnov test for the normality of different parameters showed a normal distribution only for BMI, HDL cholesterol and apolipoprotein A. Comparison of means were performed by 1-way analysis of variance based on Fisher statistics. Correlations between Hcy concentrations and the different parameters were evaluated using Spearman correlation coefficient. Significant differences between groups were performed by Tukey honestly significant differences method. $P$ values $<0.05$ were considered significant.

\section{Results}

The mean Hcy level of the study group was 19.1 (SD 5.6) $\mu \mathrm{mol} / \mathrm{L}$. There were 541 subjects with normal HCy levels $(\leq 15 \mu \mathrm{mol} / \mathrm{L})$ and 162 with elevated HCy levels (> $15 \mu \mathrm{mol} / \mathrm{L}$ ), giving a prevalence of hyperhomocysteinaemia of $22.9 \%$. Table 1 shows the mean Hcy and vitamin levels in healthy people with normal and raised Hcy by sex The mean Hcy concentration was significantly

\begin{tabular}{|c|c|c|c|c|c|c|}
\hline \multirow[t]{3}{*}{ Variable } & \multicolumn{3}{|c|}{$\begin{array}{l}\text { Normohomocysteinaemia }{ }^{a} \\
\qquad(n=541)\end{array}$} & \multicolumn{3}{|c|}{$\begin{array}{l}\text { Hyperhomocysteinaemia } \\
\qquad(n=162)\end{array}$} \\
\hline & Male & Female & $P$-value & Male & Female & $P$-value \\
\hline & Mean (SD) & Mean (SD) & & Mean (SD) & Mean (SD) & \\
\hline Hсу ( $\mu \mathrm{mol} / \mathrm{L})$ & $12.7(5.4)$ & $11.9(5.2)$ & 0.028 & $19.5(5.6)$ & $19.7(5.7)$ & NS \\
\hline Vitamin $B_{12}(p g / m L)$ & $259.4(106.3)$ & $284.7(121.1)$ & NS & $236.7(80.8)$ & 278.9 (114.9) & 0.035 \\
\hline Folates (ng/mL) & $4.31(2.40)$ & $6.13(3.06)$ & $<0.001$ & $4.32(3.61)$ & $6.06(2.69)$ & 0.031 \\
\hline
\end{tabular}

${ }^{a} \mathrm{Hcy} \leq 15 \mu \mathrm{mol} / \mathrm{L} ;{ }^{b} \mathrm{Hcy}>15 \mu \mathrm{mol} / \mathrm{L} . S D=$ standard deviation. 


\begin{tabular}{|c|c|c|}
\hline \multicolumn{3}{|c|}{$\begin{array}{l}\text { Table } 3 \text { Mean homocysteine (Hcy) levels in healthy people with raised } \\
\text { homocysteine in relation to demographic factors }\end{array}$} \\
\hline Variable & Hyperhomocysteinaemia $^{a}$ & $P$-value \\
\hline & Hcy $(\mu \mathrm{mol} / \mathrm{L})(n=162)$ & \\
\hline & Mean (SD) & \\
\hline \multicolumn{3}{|l|}{ Alcohol user } \\
\hline No & $19.6(5.8)$ & \\
\hline Yes & $18.0(3.4)$ & $<0.03$ \\
\hline \multicolumn{3}{|l|}{ Tobacco user } \\
\hline No & $20.3(6.8)$ & $>0.05$ \\
\hline Yes & $18.7(4.1)$ & \\
\hline$B M I$ & & $>0.05$ \\
\hline Normal weight & $18.9(4.5)$ & \\
\hline Overweight & $20.3(7.1)$ & \\
\hline
\end{tabular}

${ }^{a} \mathrm{Hcy}>15 \mu \mathrm{mol} / \mathrm{L}$

$S D=$ standard deviation $; B M I=$ body mass index

higher in men than women in the subgoup with normal homocysteine levels [12.7 (SD 5.4) versus 11.9 (SD 5.2) $\mu \mathrm{mol} / \mathrm{L}](\mathrm{P}=0.028)$ but not in the subgroup with elevated homocysteine levels [19.5 (SD 5.6) versus 19.7 (SD 5.7)].

In the normohomocysteinaemia group there were no difference in Hcy levels by region whereas in the hyperhomocysteinaemia group the mean Hcy level was significantly higher in the central region of the country compared with the capital, Tunis city and the southern region (Table 2).

Vitamin $B_{12}$ level was significantly higher in Tunis city than in the central region In the normohomocysteinaemia group but not in the hyperhomocysteinaemia group (Table 2). Folate levels did not vary by region in either subgroup.

In subjects with hyperhomocysteinaemia the mean Hcy level was significantly lower in those consuming alcohol compared with those not drinking alcohol [18.0 (3.4) $\mu \mathrm{mol} / \mathrm{l}$ versus $20.3(6.8) \mu \mathrm{mol} / \mathrm{L}](P<0.05)$ (Table $3)$. There were no significantly differences by smoking and BMI status.

Subjects with hyperhomocysteinaemia had significantly elevated lipid parameters - total cholesterol,
LDL cholesterol, apolipoprotein A and apolipoprotein $\mathrm{B}$ - and lower vitamin $B_{12}$ levels compared with those with normohomocysteinaemia (Table 4).

In all studied population, Hcy levels correlated with total cholesterol $(r=0.09, P<0.05)$, apolipoprotein A $(r=0.012, P<0.01)$ and apolipoprotein $\mathrm{B}(r=0.013, P<0.01)$.

\section{Discussion}

In the present study the prevalence of hyperhomocysteinaemia was $22.9 \%$ in this sample of healthy people in Tunisia and the mean value was 12.6 (SD 5.4) $\mu \mathrm{mol} / \mathrm{L}$. The distribution of Hcy in different geographic regions of Tunisia was not homogenous; we found differences in Hcy distribution between residents of the capital city and the centre region of Tunisia but only among those with hyperhomocysteinaemia. Previous studies have reported Hcy concentrations ranging from $6 \mu \mathrm{mol} / \mathrm{L}$ in Japan to $13 \mu \mathrm{mol} / \mathrm{L}$ in South Africa in healthy subjects [4]. In the Iranian population, Hcy concentrations were lower [7.4 (SD 3.2) $\mu \mathrm{mol} / \mathrm{L}]$ compared with our sample [12.6 (SD 5.4) $\mu \mathrm{mol} / \mathrm{L}$ ] [5] and compared with Syrian healthy subjects $(11.3 \mu \mathrm{mol} / \mathrm{L})[6]$ and Moroccan healthy subjects $[11.3$ (SD 3.1) 


\begin{tabular}{|c|c|c|c|}
\hline Variable & $\begin{array}{l}\text { Normohomocysteinaemia }^{a} \\
\qquad(n=541)\end{array}$ & $\begin{array}{l}\text { Hyperhomocysteinaemia } \\
\qquad(n=162)\end{array}$ & $P$-value \\
\hline & Mean (SD) & Mean (SD) & \\
\hline Vitamin $B_{12}(p g / m L)$ & $271.2(115.2)$ & $242.7(87.2)$ & $<0.01$ \\
\hline Folates $(\mathrm{ng} / \mathrm{mL})$ & $4.63(2.21)$ & $4.55(3.54)$ & $>0.05$ \\
\hline Total cholesterol (mmol/L) & $4.01(1.08)$ & $4.22(1.10)$ & $<0.05$ \\
\hline HDL cholesterol (mmol/L) & $0.97(0.22)$ & $1.00(0.21)$ & $>0.05$ \\
\hline Total/HDL cholesterol ratio & $4.33(1.98)$ & $4.24(1.05)$ & $>0.05$ \\
\hline LDL cholesterol (mmol/L) & $2.32(0.87)$ & $2.49(1.09)$ & $<0.01$ \\
\hline Triglycerides (mmol/L) & $1.50(1.00)$ & $1.53(1.05)$ & $>0.05$ \\
\hline Apo A (g/L) & $1.19(0.26)$ & $1.25(0.27)$ & $<0.05$ \\
\hline Apo B (g/L) & $0.73(0.25)$ & $0.78(0.29)$ & $<0.05$ \\
\hline Apo B/A ratio & $0.61(0.41)$ & $0.62(0.20)$ & $>0.05$ \\
\hline $\mathrm{Lp}$ a $(\mathrm{g} / \mathrm{L})$ & $0.12(0.11)$ & $0.11(0.10)$ & $>0.05$ \\
\hline
\end{tabular}

${ }^{a} \mathrm{Hcy} \leq 15 \mu \mathrm{mol} / \mathrm{L} ;{ }^{b} \mathrm{Hcy}>15 \mu \mathrm{mol} / \mathrm{L}$.

$S D=$ standard deviation; $H D L=$ high-density lipoprotein $L D L=$ low-density lipoprotein; Apo $A=$ apolipoprotein $A ;$ Apo B =apolipoprotein $B ; L$ a $a=$ lipoprotein (a)

umol/L] [7]. The similar levels of Hcy in Syria and Morocco compared with our findings may be due to similarities in food intake habits.

In the literature, the reasons for variations of plasma Hcy between different countries are not clear. Alfthan et al. argued that intercountry differences in $\mathrm{Hcy}$ levels were real and were not due to different sampling or assay procedures [8]. We think that geographical variations in dietary fruit and vegetable intake might explain these intercountry differences between European and Mediterranean countries. In healthy populations, a correct nutritional regimen with sufficient daily intakes of the nutritional determinants of Hcy metabolism is crucial for maintaining Hcy plasma concentrations within the normal range [9]. It has been suggested that a high dietary intake of folate can make a substantial contribution to a reduction in plasma Hcy concentrations in the general population. In fact, each $3 \mu \mathrm{mol} / \mathrm{L}$ decrease in Hcy may be associated with a $16 \%$ reduction in the risk of ischaemic heart disease, $25 \%$ in the risk of deep vein thrombosis and $24 \%$ in the risk of stroke [1].

Differences in Hcy and folates levels between men and women may be due to differences in lifestyle, such as tobacco use [10] and coffee drinking (which has been demonstrated to diminish vitamin $B$ absorption [11]). In our study all the tobacco smokers were men, who in Tunisia generally consume coffee while smoking. Syrian smokers had lower folates levels compared with ex-smokers and never smokers, a fact which may have explained the higher Hcy levels found in men than women [6]. In the literature, differences in Hcy concentrations between men and women have been explained by the effect of oestrogen on Hcy metabolism [12], with remethylation being more effective in premenopausal women than in men. This hypothesis is supported by the decreased levels of Hcy after hormone treatment in menopausal women [13].

Tobacco smoking is considered to be a CVD risk factor. Jendricko $\mathrm{T}$ et al. found that war veterans who were nonsmokers had higher Hcy levels than did smokers [14]. Other studies found a positive correlation between Hcy levels and tobacco use [15] and significantly lower plasma concentrations of pyridoxal phosphate in smokers compared with non-smokers [16]. Smokers with high plasma Hcy are at greatly increased risk of CVD. These subjects had reduced levels of $B$ vitamins that modulate Hcy metabolism [10]. In our results, low Hcy concentrations in men may have been due, in part, to the effect of alcohol consumption, as alcohol drinkers had significantly lower Hcy levels. In fact studies have reported the favourable action of alcohol on lowering Hcy, and that this depends on the type of alcoholic beverage $[17,18]$.

Boushey et al. estimated that an elevation of $5 \mu \mathrm{mol} / \mathrm{L}$ in Hcy levels is equivalent to an increase of $20 \mathrm{mg} /$ dL in cholesterol [19]. Hcy has been demonstrated to induce both atherogenic and thrombogenic mediators in cultured vascular cells [20] and cause endothelial dysfunction in humans $[21,22]$. In fact, increasing synthesis of Hcy may have an effect on the progression of atherogenesis [23,24]. Yadav et al., however, did not find a significant correlation between plasma Hcy and total cholesterol, HDL cholesterol or triglycerides [25]. Holven et al. suggested that hyperhomocysteinaemic individuals have dysfunctional HDL particles with attenuated antiatherogenic activity and that this may represent a novel explanation for the increased risk of cardiovascular events in these individuals [26]. In a recent study, Zinellu et al. demonstrated that intracellular reactive oxygen species production induced by Hcy-S-LDL might be responsible for the observed human 
endothelial cells damage and indicated that Hcy-S-LDL may have some role in CVD [27]. Other lipid parameters are also demonstrated to have a role in CVD. Low apolipoprotein A, high apolipoprotein $B$ and apolipoprotein $\mathrm{B} / \mathrm{A}$ ratio were recently considered as new risk factors for CVD [28,29]. In the Atherosclerosis Risk in Communities study, apolipoprotein A was found to be strongly predictive when considered alone, but did not contribute to the risk prediction when considered with LDL cholesterol, HDL cholesterol and
TG [30]. A prospective study from the United Kingdom in men followed up for 6 years, showed that apolipoprotein $B$ was a better predictor of risk than total cholesterol or LDL cholesterol and that the ratio of apolipoprotein B/A was associated with the strongest effect on risk [31]. In a recent research, Ravnskov et al. demonstrated that homocysteine thiolactone reacted with the free amino groups of apolipoprotein-B to form homocysteinylated LDL lipoprotein and caused obstruction of the circulation in the vasa vasorum [32].

\section{Conclusion}

The elevation of Hcy levels is considered as a risk factor for CVD. In this study of healthy young adults, hyperhomocysteinaemia was associated with significantly elevated total cholesterol, LDL cholesterol, apolipoprotein A and apolipoprotein B and lower vitamin $B_{12}$ levels compared with subjects with normohomocysteinaemia. Further epidemiological studies are needed to determine the precise role of Hcy.

\section{References}

1. Wald DS et al. Homocysteine and cardiovascular disease: evidence on causality from a meta-analysis. British Medical Journal, 2002, 325:1202-1206.

2. Van Oijen $\mathrm{N}$ et al. Prognostic value of free plasma homocysteine levels in patients hospitalized with acute coronary syndrome. American Journal of Cardiology, 2008, 102:135-139.

3. Lawrence de Koning AB et al. Hyperhomocysteinemia and its role in the development of atherosclerosis. Clinical Biochemistry, 2003, 36:431-441.

4. Ueland PM et al. Total homocysteine in plasma or serum: methods and clinical applications. Clinical Chemistry, 1993, 39:1764-1779.

5. Golbahar J et al. Distribution of plasma total homocysteine concentrations in the healthy Iranians. Clinical Biochemistry, 2004, 37:149-151.

6. Herrmann $\mathrm{W}$ et al. Hyperhomocysteinemia and vitamin B-12 deficiency are more striking in Syrians than in Germans-causes and implications. Atherosclerosis, 2003, 166:143-150.

7. Bennouar $\mathrm{N}$ et al. Thermolabile methylenetetrahydrofolate reductase C677T polymorphism and homocysteine are risk factors for coronary artery disease in Moroccan population. Journal of Biomedicine and Biotechnology, 2007, 2007(1):80687.

8. Alfthan G et al. Plasma homocysteine and cardiovascular disease mortality. Lancet, 1997, 48:349-397.

9. Kudlackova KM et al. Nutritional determinants of plasma homocysteine. Bratislavske Lekarske Listy, 2007, 108:510-515.

10. O'Callaghan P et al. European COMAC group. Smoking and plasma homocysteine. European Heart Journal, 2002, 23:1559-1560.

11. Ulvik A et al. Coffee consumption and circulating B-vitamins in healthy middle-aged men and women. Clinical Chemistry, 2008, 54:1418-1420.

12. Bogdan $\mathrm{C}$ et al. Hormones and homocysteine [Hormones et homocystéine]. Sang Thrombose et Vaisseaux, 2000, 12:564568.

13. Morris MS et al. Total homocysteine and estrogen status indicators in the third national health and nutrition examination survey. American Journal of Epidemiology, 2000, 152:140-148.

14. Graham IM et al. Plasma homocysteine as a risk factor for vascular disease: The European Concerted Action Project. Journal of the American Medical Association, 1997, 277:1775-1787.
15. Jendricko T et al. Homocysteine and serum lipids concentration in male war veterans with posttraumatic stress disorder. Progress in Neuro-Psychopharmacology and Biological Psychiatry, 2009, 33:134-140.

16. Robinson $\mathrm{K}$ et al. Hyperhomocysteinemia and low pyridoxal phosphate: common and independant reversible risk factors for coronary arterydisease. Circulation, 1995, 92:2825-2830.

17. Schlienger JL. Homocystéine et consommation d'alcool: une relation ambigüe et un nouveau paradoxe [Homocysteine and alcohol consumption: an ambiguous relationship and a new paradox]. La Presse Medicale, 2003, 32:262-267.

18. Schlienger JL. Consommation modérée d'alcool et maladies cardiovasculaires. Pathologie Biologie, 2001, 49:769-774.

19. Boushey CJ et al. A quantitative assessment of plasma homocysteine as a risk factor for vascular disease: probable benefits of increasing folic acid intakes. Journal of the American Medical Association, 1995, 274:1049-1057.

20. Jamaluddin MS et al. DNA methylation and vascular disease. Clinical Chemistry and Laboratory Medicine, 2007, 45:16601666.

21. Sipkens JA et al. Homocysteine affects cardiomyocyte viability: concentration-dependent effects on reversible flip-flop, apoptosis and necrosis. Apoptosis, 2007, 12:1407-1418.

22. Levrand $\mathrm{S}$ et al. Homocysteine induces cell death in $\mathrm{H} 9 \mathrm{C} 2$ cardiomyocytes through the generation of peroxynitrite. Biochemistry and Biophysical Research, 2007, 359:445-450.

23. McCully KS et al. Homocysteine and lipid metabolism in atherogenesis: effect of the homocysteine thiolactonyl derivatives, thioretinaco and thioretinamide. Atherosclerosis, 1990, 83:197-206.

24. Hiroyuki M et al. Diet-induced hyperhomocysteinemia exacerbates neointima formation in rat carotid arteries after balloon injury. Circulation, 2001, 103:133-139.

25. Yadav AS et al. Relationship of plasma homocysteine with lipid profile parameters in ischemic heart disease. Indian Journal of Clinical Biochemistry, 2006, 21:106-110.

26. Holven KB et al. The antiatherogenic function of HDL is impaired in hyperhomocysteinemic subjects. Journal of Nutrition, 2008, 138:2070-2075.

27. Zinellu A et al. S-homocysteinylated LDL apolipoprotein B adversely affects human endothelial cells in vitro. Atherosclerosis, 2009, 206(1):40-46. 
28. Christa $\mathrm{M}$ et al. Prognostic value of apolipoprotein B and A-I in the prediction in the prediction of myocardial infarction in middle-aged men and women: results from the MONICA/ KORA Augsburg cohort study. European Heart Journal, 2005, 26:271-278.

29. Goswami B et al. Apo-B/apo-Al ratio: a better discriminator of coronary artery disease risk than other conventional lipid ratios in Indian patients with acute myocardial infarction. Acta Cardiologica, 2008, 63:749-755.

30. Sharrett AR et al. Coronary heart disease prediction from lipoprotein cholesterol levels, triglycerides, lipoprotein (a), apolipoprotein A-1 and B, and HDL density subfractions. The
Atherosclerosis Risk in Communities (ARIC) study. Circulation, 2001, 104:1108-1113.

31. Talmud PJ et al. Non fasting apolipoprotein B and triglycerides levels as a useful predictor of coronary heart disease risk in middle-aged UK men. Arteriosclerosis, Thrombosis, and Vascular Biology, 2002, 22:1918-1923.

32. Ravnskov $U$ et al. Review and hypothesis: Vulnerable plaque formation from obstruction of vasa vasorum by homocysteinylated and oxidized lipoprotein aggregates complexed with microbial remnants and LDL autoantibodies. Annals of Clinical and Laboratory Science, 2009, 39:3-16.

\section{Global atlas on cardiovascular disease prevention and control}

The Global atlas on prevention and control of cardiovascular diseases is the second Atlas on the worldwide epidemic of cardiovascular diseases published by the World Health Organization (WHO). Cardiovascular diseases lead the noncommunicable diseases epidemic contributing to nearly one third of global deaths; 17.3 million deaths a year.

The 2011 Atlas has been compiled mainly using publications and databases produced and maintained by WHO and contains chapters on death and disability, behavioural and metabolic risk factors and determinants, evidence-based interventions for prevention and control, primary health care, inequities, implementation gaps, policies, strategies, Best Buys, health in all policies and monitoring in relation to cardiovascular diseases.

The striking differences in death, disability and trends in cardiovascular diseases between high-income countries and low- and middle-income countries described in this publication, are largely related to differences in public policies within as well as outside the health sector, availability of financial resources for health, prevention and early detection practices, capacity of the health workforce, accessibility to diagnosis and treatment and primary care services. The Atlas also provides a baseline for monitoring trends and assessing progress made by countries in addressing the cardiovascular epidemic.

Further information about this and other WHO publications is available at: http://www.who.int/publications/en/ 